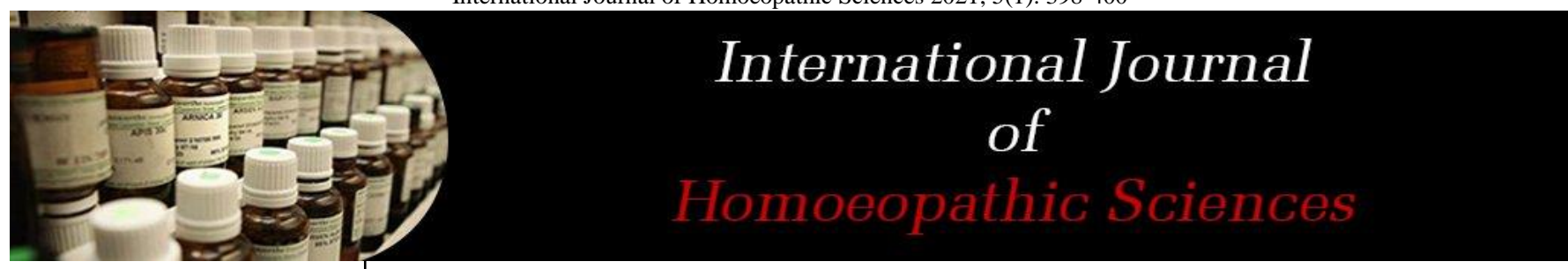

E-ISSN: 2616-4493 P-ISSN: 2616-4485 www.homoeopathicjournal.com IJHS 2021; 5(1): 398-400 Received: 01-11-2020 Accepted: 03-12-2020

Dr. Pradeep Shinde M.D. Hom, Department of Paediatric, Guru Mishri Homoeopathic Medical College, Shelgaon, Jalna, Maharashtra, India

Dr. Shaikh Nowani M.D. Hom,

Professor and PG- Guide, Department of Paediatric, Guru Mishri Homoeopathic Medical College Shelgaon, Jalna, Maharashtra, India

Corresponding Author: Dr. Shaikh Nowani M.D. Hom,

Professor and PG- Guide, Department of Paediatric, Guru Mishri Homoeopathic Medical College Shelgaon, Jalna, Maharashtra, India

\section{Childhood diarrhoea and homoeopathic management}

\author{
Dr. Pradeep Shinde and Dr. Shaikh Nowani
}

DOI: https://doi.org/10.33545/26164485.2021.v5.i1g.342

Abstract

Childhood diarrhoea is the most frequent gastroenterological disorder, and the main cause of dehydration in childhood. It is manifested by a sudden occurrence of three or more watery or loose stools per day lasting for seven to 10 days, 14 days at most. It mainly occurs in children until five years of age and particularly in neonates in the second half-year and children until the age of three years.

Keywords: gastrointestinal infections, viral and bacterial infections, malnutrition and more rarely alimentary intoxications and other factors

\section{Introduction}

Diarrhoeal disease is the second leading cause of death in children under five years old, and is responsible for killing around 55000 children every year. Diarrhoea can last several days, and can leave the body without the water and salts that are necessary for survival. In the past, for most children's, severe dehydration and fluid loss were the main causes of diarrhoea deaths. Now, other causes such as septic bacterial infections are likely to account for an increasing proportion of all diarrhoea-associated deaths.

\section{Definition}

Diarrhoea is defined as the passage of three or more loose or liquid stools per day (or more frequent passage than is normal for the individual). Frequent passing of formed stools is not diarrhoea, nor is the passing of loose, "pasty" stools by breastfed babies.

\section{Causes of Diarrhoea}

Infection: Diarrhoeais caused by a host of bacterial, viral and parasitic organisms. Infection is more common when there is a shortage of adequate sanitation and hygiene and safe water for drinking, cooking and cleaning. Rotavirus and Escherichia coli, are the two most common etiological agents of moderate-to-severe diarrhoea in low-income countries.

Malnutrition: Children who die from diarrhoea often suffer from underlying malnutrition, which makes them more vulnerable to diarrhoea. Each diarrhoeal episode, in turn, makes their malnutrition even worse.

Food poisoning: Can also cause diarrhoea in kids. Symptoms usually come on quickly, may include vomiting, and tend to go away within 24 hours.

Two functional GI disorders that cause chronic diarrhoea in children are toddler's diarrhoea and irritable bowel syndrome (IBS).

\section{Toddler's diarrhoea}

Toddler's diarrhoea - also called functional diarrhoea, or chronic nonspecific diarrhoea of childhood - is a common cause of chronic diarrhoea in toddlers (ages 1 to 3), and preschoolage children (ages 3 to 5).

\section{Symptoms of Diarrhea}

Severe dehydration (at least two of the following signs)

- lethargy/unconsciousness, sunken eyes, unable to drink or drink poorly, skin pinch goes back very slowly ( $\geq 2$ seconds )

- $\quad$ Some dehydration (two or more of the following signs):restlessness, irritability, sunken eyes, drinks eagerly, thirsty. 
- Cramping and Belly (abdominal) pain, Swelling (bloating).

- Upset stomach (nausea), Urgent need to use the bathroom

Fever with Bloody stools.

- Chilhood Diarrhoea can be diagnosed:

- Child may have lab tests to check blood and urine.

- A stool culture to check for abnormal bacteria or parasites in your child's digestive tract. A small stool sample is taken and sent to a lab.

- A stool evaluation to check the stool for blood or fat

- Imaging tests to rule out structural problems

- Tests to check for food intolerance or allergies

- A sigmoidoscopy. This test lets the healthcare provider check the inside of part of your child's large intestine.

\section{Prevention and treatment}

- Key measures to prevent diarrhoea include:

- access to safe drinking-water; use of improved sanitation;

- $\quad$ exclusive breastfeeding for the first six months of life;

- health education about how infections spread; and

- rotavirus vaccination.

- Zinc supplements: zinc supplements reduce the duration of a diarrhoea episode by $25 \%$ and are associated with a $30 \%$ reduction in stool volume.

- Rehydration: with intravenous fluids in case of severe dehydration or shock.

\section{Homoeopathic Management}

- Arsenicum album: This remedy relieves foul-smelling, burning diarrhoea from food poisoning, associated with weakness and relieved by heat or hot food.

- Bryonia: This remedy is often helpful for diarrhoea during flu (especially when the person feels grumpy and wants to lie still and be left alone). It may also be helpful for diarrhoea that occurs when a person gets overheated, then drinks a lot of cold water.

- Chamomilla: Hot, green, watery diarrhoea with abdominal pain and gas suggests a need for this remedy.

- Gelsemium: This remedy is often indicated if trembling and weakness accompany diarrhoea, especially when nervousness, fear, or emotional upset is the cause.

- Pulsatilla: If diarrhoea occurs after eating rich and fatty foods, this remedy can be helpful. Queasiness and abdominal pain are likely to occur, and the diarrhoea has a changeable appearance.

- Conclusion: Promote national policies and investments that support case management of diarrhoea and its complications as well as increasing access to safe drinking-water and sanitation in developing areas in country ; build capacity in implementing preventive interventions, including sanitation, source water improvements, and household water treatment and safe storage; develop new health interventions, such as the rotavirus immunization.

\section{References}

1. Acute diarrhoeal diseases--an approach to management, Dipika Sur, S K Bhattacharya.

2. Management of acute diarrhoea. Bhattacharya SK. Indian J Med Res.
3. Diarrhoeal disease explained under section of world health organisation.

4. Homoeopathic medicine in diarhoea; homoeopathic.com

5. Kosek M, Bern C, Guerrant R. The global burden of diarrhoeal disease, as estimated from studies published between 1992 and 2000. Bull World Health Organ 2003;81:197-204.

6. Global Burden of Disease 2013 Mortality and Causes of Death Collaborators. Global, regional, and national agesex specific all-cause and cause-specific mortality for 240 causes of death, 1990-2013: a systematic analysis for the Global Burden of Disease Study 2013. Lancet 2015;385:117-171.

7. Bustreo F, Okwo-Bele JM, Kamara L. World Health Organization perspectives on the contribtion of the Global Alliance for Vaccines and Immunization on reducing child mortality. Arch Dis Child 2015;100(Suppl. 1):S34:S37.

8. Alexander KA, Blackburn JK. Overcoming barriers in evaluating outbreaks of diarrheal disease in resource poor settings: assessment of recurrent outbreaks in Chobe District, Botswana. BMC Public Health 2013;13:775.

9. Global Burden of Diarrhoeal Diseases Collaborators. Estimates of global, regional, free al morbidity, mortality, and aetiologies of diarrhoeal diseases: a systematic analysis for the Global Burden of Disease Study 2015. Lancet Infect Dis 2017;17:909-948.

10. Kotloff KL, Nataro P, Blackwelde WC et al. Burden and aetiology of diarrhoeal disease in infants and young children in developing countries (the Global Enteric Multicenter Study, GEMS): a prospective, case-control study. Lancet 2013;382:209-222.

11. Fiedoruk K, Daniluk T, Rozkiewicz D et al. Conventional and molecular methods in the diagnosis of community-acquired diarrhoea in children under 5 years of age from the north-eastern region of Poland. Int J Infect Dis 2015;37:145-151.

12. Sidoti F, Rittà M, Costa C et al. Diagnosis of viral gastroenteritis: limits and potential of currently available procedures. J Infect DevCtries 2015. Adi BS. Efficacy of homoeopathic medicines in chronic low back pain: A clinical study. International Journal of Alternative and Complementary Medicine 2020;9:P1720, 551-561.

13. Oloruntoba EO, Folarin TB, Ayede AI. Hygiene and sanitation risk factors of diarrhoeal disease among under-five children in Ibadan, Nigeria. Afr Health Sci 2014;14:1001-1011.

14. Scharf RJ, Deboer MD, Guerrant RL. Recent advances in understanding the long-term free of childhood infectious diarrhea. Curr Infect Dis Rep 2014;16:408.

15. Bulled N, Singer M, Dillingham R. The syndemics of childhood diarrhoea: a biosocial pective on efforts to combat global inequities in diarrhoea-related morbidity and mortality. Glob Public Health 2014;9:841-853.

16. Reddington K, Tuite N, Minogue E et al. A current overview of commercially available cleic acid diagnostics approaches to detect and identify human gastroenteritis pathogens. Biomol Detect Quantif 2014;1:3-7.

17. Kosek M, Bern C, Guerrant RL. The magnitude of the global burden of diarrhoeal disease rom studies 
published 1992-2000. Bull WHO 2003;81:197-204.

18. Parashar UD, Bresee JS, Glass RI. The global burden of diarrhoeal disease in children. ull WHO 2003;81:236.

19. Chowdhury F, Rahman MA, Begum YA et al. Impact of rapid urbanization on the rates of infection by Vibrio cholerae $\mathrm{O} 1$ and enterotoxigenic Escherichia coli in Dhaka, Bangladesh. PLoSNegl Trop Dis 2011;5:e999.

20. Alexander KA, Carzolio M, Goodin D et al. Climate change is likely to worsen the public health threat of diarrheal disease in Botswana. Int $\mathrm{J}$ Environ Res Public Health 2013;10:1202-1230.

21. Wiens MO, Pawluk S, Kissoon N et al. Pediatric postdischarge mortality in resource poor countries: a systematic review. PLoS ONE 2013;8:e66698.

22. Pernica JM, Steenhoff AP, Welch H et al. Correlation of clinical outcomes with multiplex molecular testing of stool from children admitted to hospital with gastroenteritis in Botswana. J Pediatric Infect Dis Soc 2016;5:312-318.

23. MacIntyre J, McTaggart J, Guerrant RL et al. Early childhood diarrhoeal diseases and cognition: are we missing the rest of the iceberg? Paediatr Int Child Health 2014;34:295-307.

24. Victora CG, Adair L, Fall C et al. Maternal and child undernutrition: consequences for adult health and human capital. Lancet 2008;371:340-357. 